Jurnal Indonesia Sosial Teknologi:p-ISSN: 2723 - 6609

e-ISSN :2745-5254

Vol. 3, No.1 Januari 2022

\title{
RANCANG BANGUN ALAT SCREW EXTRUDER PEMBUATAN MEDIUM DENSITY FIBERBOARD BERBASIS SERAT TANDAN KOSONG KELAPA SAWIT DAN PEREKAT HIGH DENSITY POLYETHYLENE (HDPE) (UJI KINERJA ALAT DITINJAU DARI EFISIENSI SCREW EXTRUDER)
}

\author{
Muhamad Arif Rachman ${ }^{1}$, Anerasari Meidinariasty ${ }^{2}$, Selastia Yuliati ${ }^{3}$ \\ Program Studi Teknologi Kimia Industri, Politeknik Negeri Sriwijaya ${ }^{1,2,3}$ \\ Email: m.arifrachman12@gmail.com ${ }^{1}$, anerasari@ polsri.ac.id ${ }^{2}$, \\ selastiayuliati@yahoo.com³.
}

\begin{abstract}
Abstrak
Penelitian rancang bangun prototipe alat Single Screw Extruder bertujuan untuk menghasilkan produk Medium Density Fiberboard (MDF) atau papan kayu berkerapatan sedang dengan bahan baku serat Tandan Kosong Kelapa Sawit (TKKS) dan perekat dari limbah plastik High Density Polyethylene (HDPE) yang sesuai dengan SNI 01-4449-2006. Pembuatan MDF dari bahan baku limbah TKKS dan HDPE ini diharapkan dapat menangani permasalahan limbah belum termanfaatkan dengan baik sekaligus mengolahnya menjadi produk bernilai jual demi mengatasi urgensi kebutuhan manusia akan papan kayu. Rancang bangun alat Single Screw Extruder ini dilakukan dengan memodifikasi insulasi pada barrel dan penggunaan inverter atau Speed Drive (VSD) pada motor penggerak. Penelitian ini memvariasikan temperatur pemanasan sebesar $210^{\circ} \mathrm{C}, 230^{\circ} \mathrm{C}$, dan $250^{\circ} \mathrm{C}$; serta putaran screw sebesar $20 \mathrm{rpm}, 40 \mathrm{rpm}$, dan $60 \mathrm{rpm}$. Dilakukan pengujian terhadap produk papan serat yang dihasilkan sesuai dengan SNI 01-4449-2006 dan didapat nilai kerapatan tertinggi sebesar $0,9843 \mathrm{~g} / \mathrm{cm} 3$; nilai daya serap terhadap air terendah sebesar 9,39\%; nilai kadar air terendah sebesar $1,57 \%$; dan nilai pengembangan tebal terendah sebesar $3,41 \%$.
\end{abstract}

Kata kunci: Screw Extruder; Papan Serat Berkerapatan Sedang; Tandan Kosong Kelapa Sawit; High Density Polyethylene.

\section{Abstract}

Research on the design of a prototype of a Single Screw Extruder aims to produce Medium Density Fiberboard (MDF) using raw materials of Oil Palm Empty Fruit Bunches (OPEFB) and adhesives from High-Density Polyethylene (HDPE) plastic waste under SNI 01 - 4449-2006. The manufacture of MDF from EFB and HDPE waste is expected to deal with the problem of waste that has not been utilized properly and to overcome the human need for wooden boards. The design of the Single Screw Extruder is done by modifying the insulation on the barrel and using an inverter or Variable Speed Drive (VSD) on the driving motor. This study varied the heating temperature by $210^{\circ} \mathrm{C}, 230^{\circ} \mathrm{C}$, and $250^{\circ} \mathrm{C}$; and screw rotation of 20 rpm, $40 \mathrm{rpm}$, and $60 \mathrm{rpm}$. Tests were carried out on fiberboard products produced under SNI 01-4449-2006 and obtained the highest density value of $0.9843 \mathrm{~g} / \mathrm{cm} 3$; 
Muhamad Arif Rachman, Anerasari Meidinariasty, Selastia Yuliati.

the lowest water absorption value is $9.39 \%$; the lowest water content value is $1.57 \%$, and the lowest thickness expansion value is $3.41 \%$.

Keywords: Single Screw Extruder; Composites; Medium Density Fiber Board; Oil Palm Empty Fruit Bunches; High Density Polyethylene Waste.

\section{Pendahuluan}

Komposit merupakan kombinasi dari dua bahan atau lebih untuk menghasilkan material baru dengan sifat yang unik dibandingkan sifat material dasar sebelum dicampur dan terjadi ikatan permukaan antara masing-masing material penyusun (Apriani, 2017). Salah satu keuntungan material komposit adalah kemampuan material tersebut untuk dapat diarahkan, sehingga kekuatannya dapat diatur hanya pada arah tertentu yang kita kehendaki, atau dapat disebut sebagai tailoring properties (Apriani, 2017). Beberapa sifat istimewa dari komposit, yaitu ringan, kuat, tidak terpengaruh korosi, dan mampu bersaing dengan logam, dengan tidak kehilangan karakteristik dan kekuatan mekanisnya.

Seiring dengan meningkatnya kebutuhan manusia akan papan dari tahun ke tahun memberi pengaruh kurang baik terhadap alam. Hasil hutan terutama bahan kayu lamakelamaan akan terus berkurang ditambah dengan adanya penebangan liar (illegal logging) menyebabkan pengambilan hasil hutan menjadi tidak terkontrol. Salah satu upaya untuk menghentikan ketergantungan manusia dengan papan berbahan dasar kayu adalah dengan mencari substitusi bahan yang memiliki sifat yang sama atau lebih unggul daripada produk kayu hutan. Papan serat merupakan panel yang dihasilkan dari pengempaan serat kayu atau bahan ber-lignoselulosa lain dengan ikatan utama berasal dari bahan baku yang bersangkutan (khususnya lignin) atau bahan lain (khususnya perekat) untuk memperoleh sifat khusus (Badan Standardisasi Nasional, 2006).

Syarat terpenting dalam pembuatan papan serat adalah menggunakan bahan dengan kandungan utama selulosa. Salah satu bahan yang bisa menjadi alternatif adalah limbah tandan kosong kelapa sawit (TKKS). TKKS merupakan hasil akhir dari kelapa sawit yang masih sangat terbatas penggunaannya sehingga cenderung dikategorikan sebagai limbah. Tiap kandungan serat TKKS secara fisik mengandung bahan-bahan serat seperti lignin $(16,19 \%)$, selulosa $(44,14 \%)$ dan hemi selulosa $(19,28 \%)$ yang mirip dengan bahan kimia penyusun kayu (Safrijal dkk., 2017). Luasnya lahan kelapa sawit di Indonesia khususnya di Sumatera yaitu sebesar 6,37 Mha atau 63.700 kilometer persegi pada tahun 2017 menandakan potensi akan TKKS yang sangat besar sebagai bahan baku utama dari papan serat.

Salah satu limbah plastik yang umum ditemui di lingkungan adalah limbah plastik berjenis High Density Polyethylene (HDPE). HDPE berasal dari gabungan monomer jenis Ethylene $\left(\mathrm{C}_{2} \mathrm{H}_{4}\right)$ yang mengalami proses polimerisasi dengan tekanan rendah. Plastik HDPE memiliki kekuatan mekanik yang tinggi, transparan, tidak beracun, dan tidak memiliki pengaruh pada rasa dan permeabilitas yang dapat diabaikan untuk karbon dioksida (Silviyati dkk., 2019). HDPE memiliki kekuatan tarik dan impak yang 
Rancang Bangun Alat Screw Extruder Pembuatan Medium Density Fiberboard Berbasis Serat Tandan Kosong Kelapa Sawit dan Perekat High Density Polyethylene (Hdpe) (Uji

Kinerja Alat Ditinjau dari Efisiensi Screw Extruder)

sangat baik, serta ketahanan terhadap bahan kimia, kejernihan, kemampuan proses, kemampuan warna dan stabilitas termal (Irvan, 2016 dalam Silviyati dkk., 2019). Dengan sifat fisis yang dimiliki oleh HDPE ini, sangat memungkinkan untuk menjadikannya sebagai bahan perekat dari papan serat berbahan limbah TKKS.

Berdasarkan studi yang dilakukan oleh (Ferhat dkk., 2014), meneliti sifat mekanis komposit kayu pohon pinus dan matriks plastik (Polypropylene) dengan menggunakan metode ekstruksi, maka hasil yang didapat dengan matriks polimer polypropylene sebesar 50\% dan serbuk kayu pinus 50\% menunjukan sifat fisis tertinggi. Demikian juga dengan penelitian yang dilakukan (Satito 2016), pembuatan panel komposit kayu plastik (Wood Plastic Composit) menggunakan metode screw extrusion dengan komposisi $70 \%$ serbuk kayu bingkirai dan 30\% plastik HDPE memiliki sifat fisik material dengan kerapatan $0,96 \mathrm{gram} / \mathrm{cm}^{3}$. Sedangkan penelitian yang dilakukan (Zulnazri dkk., 2014). Pembuatan material komposit plastik HDPE dengan campuran serbuk TKKS dengan metode 2 tahap yaitu screw extrusion untuk pembuatan pellet komposit dan proses pengempaan dengan hotpress.

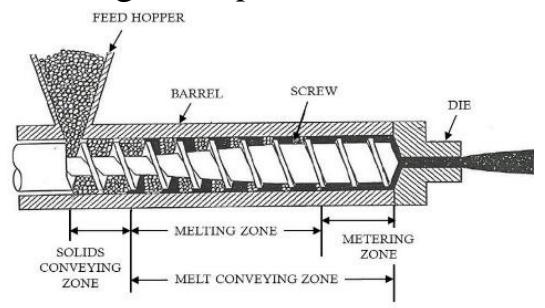

Gambar. 1 Extruder

(Kelly dkk., 2014)

Proses ekstrusi plastik dilakukan dengan 1 tahap dengan menekan bahan dasar plastik agar mengalir melalui lubang pada cetakan menghasilkan produk kontinyu yang bentuknya ditentukan oleh bentuk lubang cetakan (die) (Mikell \& Groover, 2013). Mesin ekstrusi memiliki bagian yang bernama extruder.

Extruder memiliki fungsi sebagai pelebur plastik yang nantinya akan diproses melalui zona pemanas yang memiliki suhu yang sama berdasarkan titik leleh dari plastik yang digunakan dan kemudian akan didorong keluar oleh screw conveyor untuk sampai pada bagian dies untuk berbagai macam proses selanjutnya (Maradu dkk., 2018).

Berdasarkan penelitian (Aryo Satito, 2016), dilakukan penelitan lanjutan rancang bangun alat screw extruder dengan memodifikasi insulasi pada barrel dan penggunaan Inverter yang seringkali disebut Variable Speed Drive (VSD) atau Variable Frequency Drive (VFD) pada motor penggerak. Penggunaan VSD pada motor listrik dapat menyesuaikan kecepatan screw sesuai dengan yang dibutuhkan dalam proses ekstrusi sehingga mencegah terjadinya penggunaan energi yang sia-sia dan mampu mengurangi biaya listrik (Atmam dkk., 2018), Hal ini diharapkan mampu meningkatkan efektivitas alat screw extruder dalam memproduksi papan serat berkerapatan sedang yang memenuhi sifat fisik dan mekanis berdasarkan Standar Nasional Indonesia No. 014449-2006 dengan menentukan kondisi operasi optimum pada saat proses produksi. 
Berdasarkan studi literatur yang telah diuraikan, terlihat bahwa pembentukan papan komposit pada umumnya menggunakan metode ektrusi, namun studi literatur mengenai pembuatan Medium Density Fiberboard menggunakan metode ektrusi masih terbatas. Sehingga dilakukan penelitan pembuatan Medium Denisty Fiberboard dapat dibuat dari limbah plastik sebagai perekat dan bahan isian dari tandan kosong kelapa sawit (TKKS) dengan menggunakan alat Screw Extruder. Dengan adanya pengembangan penelitian ini diharapkan dapat mengurangi dampak pencemaran lingkungan sekaligus menghasilkan produk papan serat dengan memanfaatkan bahan perekat dari limbah plastik dan bahan isian alami sebagai alternatif pengganti papan kayu yang memenuhi Standar Nasional Indonesia No. 01-4449-2006.

\section{Metode Penelitian}

Penelitian ini menggunakan metode rancang bangun dan eksperimen yang dimodifikasi dari metode pada penelitian (Aryo Satito, 2016) yang membuat rancang bangun mesin wood plastic composite screw extrusion molding untuk produksi panel komposit kayu plastik untuk dinding dan lantai. Matriks yang digunakan pada penelitian tersebut merupakan polyprophylene (PP) dan polyvinylchloride (PVC). Metode rancang bangun pada penelitian ini dilakukan untuk perancangan Screw Extruder pada pembuatan Medium Density Fiberboard (Papan Serat Berkerapatan Sedang) dengan memvariasikan temperatur operasi alat Screw Extruder sebesar $210^{\circ} \mathrm{C}, 230^{\circ} \mathrm{C}$, dan $250^{\circ} \mathrm{C}$; serta putaran screw sebesar $20 \mathrm{rpm}, 40 \mathrm{rpm}$, dan $60 \mathrm{rpm}$. Adapun metode eksperimen yang dilakukan adalah modifikasi matriks berupa plastik High Density Polyethylene (HDPE) yang dicampur dengan serat Tandan Kosong Kelapa Sawit (TKKS) dengan perbandingan 50:50. Metode eksperimen dilakukan untuk mengetahui kinerja mesin Screw Extruder pada proses ekstrusi dan pembuatan $M D F$ berbasis serat TKKS dan perekat HDPE serta hasil papan serat berkerapatan sedang yang dihasilkan diharapkan memenuhi parameter dalam SNI 01-4449-2006 yang meliputi kerapatan, kadar air, daya serap terhadap air, dan pengembangan tebal.

\section{Pendekatan Desain Fungsional}

Pada pendekatan rancang bangun alat Screw Extruder memiliki beberapa komponen beserta fungsinya yang terdiri dari :

\section{Single Screw}

Screw merupakan bagian utama pada proses ektrusi. Screw berfungsi sebagai poros pendorong dan pengaduk untuk plastik yang meleleh yang terdapat di dalam barrel yang kemudian dialirkan ke kepala die.

2. Barrel

Unit tabung pemanas yang berfungsi untuk mencairkan serbuk plastic HDPE dan mencampurkannya dengan serat TKKS. Unit ini terdiri dari tabung dan terdapat elemen pemanas yang mampu memanaskan campuran serat TKKS dan plastik. Pada saat plastik 
Rancang Bangun Alat Screw Extruder Pembuatan Medium Density Fiberboard Berbasis Serat Tandan Kosong Kelapa Sawit dan Perekat High Density Polyethylene (Hdpe) (Uji Kinerja Alat Ditinjau dari Efisiensi Screw Extruder)

mencair, plastik akan membungkus serat TKKS yang kemudian campuran serat TKKS dan plastik diekstrusikan oleh screw menuju kepala die.

3. Heater

Elemen pemanas (heater element) adalah komponen yang menghasilkan panas untuk melelehkan plastik pada mesin ekstrusi ini. Elemen ini diletakan pada bagian pengumpan (feed section), bagian penekan (compression section), bagian pengaduk (metering section) dan bagian cetakan (die temperature).

4. Motor Penggerak

Fungsi motor penggerak adalah untuk mengatur dan menggerakkan screw, yang memasok torsi dan kecepatan yang diperlukan selama proses ekstrusi.

\section{Gear Transmisi}

Gear transmisi merupakan bagian dari unit penggerak yang berfungsi untuk mereducer kecepatan motor dan meningkatkan torsi.

\section{Hopper}

Hopper berfungsi sebagai tempat memasukkan bahan baku plastik dan serat TKKS yang telah dicampur rata. Hopper umumnya dibuat dalam bentuk simetris. Pemilihan material yang baik untuk membuat hopper adalah menggunakan bahan yang ringan dan tahan korosi. Pada umumnya hopper terbuat dari aluminium dan stainless steel.

7. Sistem Kontrol

Sistem kontrol berfungsi untuk mengatur dan menjaga kondisi operasi pada saat proses ekstrusi. Sistem kontrol yang terdapat pada Temperature Zone Control berfungsi untuk mengendalikan temperatur heater sesuai yang diinginkan pada setiap zona. Kemudian terdapat sistem kontrol penggerak yaitu Variable Speed Drive (VSD) yang berfungsi mengatur dan mengendalikan putaran screw terhadap laju alir ekstrusi dan tekanan pada die.

8. Cetakan (die)

Cetakan (die) berbentuk rongga kosong yang kemudian diisi dengan material meleleh untuk memperoleh suatu bentuk yang diinginkan. Diameter lubang cetakan dibuat lebih kecil dari ukuran diameter barrel agar dapat memberikan tekanan pada saat proses pencetakan.

\section{Pendekatan Desain Struktural}

Pendekatan desain struktural menjelaskan struktur secara detail dari suatu alat, baik dari material, ukuran maupun proses pembuatannya yang dapat diamati pada Gambar 2.1. Pada gambar tersebut menyajikan rancangan alat Screw Extruder. Dalam skematik ini ditentukan posisi yang dipasang termokopel dan VSD pada proses ekstrusi. 


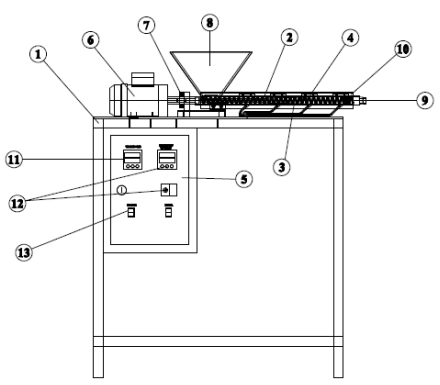

Gambar 2.1 Single Screw Extruder

Adapun alat dan bahan yang digunakan dalam rancang bangun alat Screw Extruder ini terbagi menjadi 2, yaitu pada pembuatan alat dan pada penelitian.

Penelitian rancang bangun alat Screw Extruder ini dijelaskan pada diagram alir pada Gambar 2.2. di bawah ini.

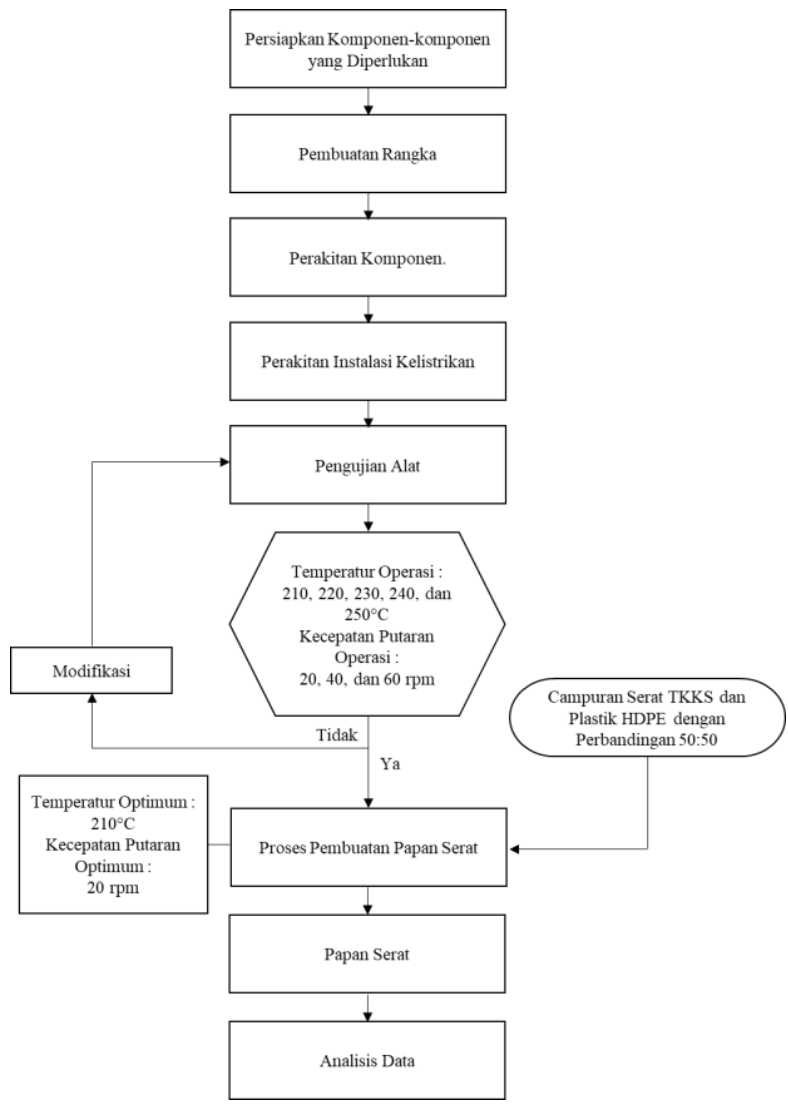

Gambar 2.2. Diagram Alir Perancangan dan Pengujian Alat Screw Extruder

Variabel bebas yang diambil pada penelitian ini meliputi temperatur pemanasan sebesar $210^{\circ} \mathrm{C}, 230^{\circ} \mathrm{C}$, dan $250^{\circ} \mathrm{C}$; serta putaran screw sebesar $20 \mathrm{rpm}, 40 \mathrm{rpm}$, dan 60 rpm. Variabel kontrol berupa komposisi bahan:perekat sebesar 50:50, dan variabel terikat berupa daya serap terhadap air, kadar aair, kerapatan, pengembangan tebal.

Analisis terhadap kelayakan papan serat berkerapatan sedang dari tandan kosong dan plastik HDPE daur ulang, dilakukan pengujian-pengujian sesuai standar SNI 01- 
Rancang Bangun Alat Screw Extruder Pembuatan Medium Density Fiberboard Berbasis Serat Tandan Kosong Kelapa Sawit dan Perekat High Density Polyethylene (Hdpe) (Uji Kinerja Alat Ditinjau dari Efisiensi Screw Extruder)

4449-2006 yang meliputi kerapatan, kadar air, daya serap terhadap air, dan pengembangan tebal.

\section{Hasil dan Pembahasan}

Dilakukan analisis terhadap laju alir dan kinerja dari alat screw extruder serta pengaruh temperatur dan kecepatan putaran screw terhadap kerapatan, kadar air, daya serap terhadap air, dan pengembangan tebal.

\section{Pengaruh Temperatur dan Kecepatan Putaran Terhadap Kerapatan pada Papan Serat}

Nilai kerapatan Medium Density Fiberboard (MDF) yang dihasilkan secara keseluruhan telah memenuhi Standar Nasional Indonesia 01-4449-2006 yang mengsyarat kerapatan pada papan serat berkerapatan sedang sebesar $0,4-0,84 \mathrm{gr} / \mathrm{cm}^{3}$. Pada penelitian ini, papan serat yang dihasilkan melebihi nilai standar papan serat berkerapatan sedang, sehingga papan serat yang dihasilkan termasuk ke dalam kategori papan serat berkerapatan tinggi atau Hardboard. Kategori ini mengacu pada klasifikasi SNI 01-4449-2006 yang membagi papan serat menjadi papan serat berkerapatan rendah (di bawah 0,40 gr/ $\left.\mathrm{cm}^{3}\right)$, papan serat berkerapatan sedang $\left(0,40-0,84 \mathrm{gr} / \mathrm{cm}^{3}\right)$ dan papan serat berkerapatan tinggi (di atas $0,84 \mathrm{gr} / \mathrm{cm}^{3}$ ). Pada Gambar 3.1, dapat dilihat bahwa nilai kerapatan yang tertinggi yaitu pada papan serat dengan temperatur operasi sebesar $250^{\circ} \mathrm{C}$ dengan kecepatan putaran screw sebesar $20 \mathrm{rpm}$. Sedangkan nilai kerapatan terendah berada pada temperatur $210^{\circ} \mathrm{C}$ dengan kecepatan putaran screw sebesar 60 rpm.

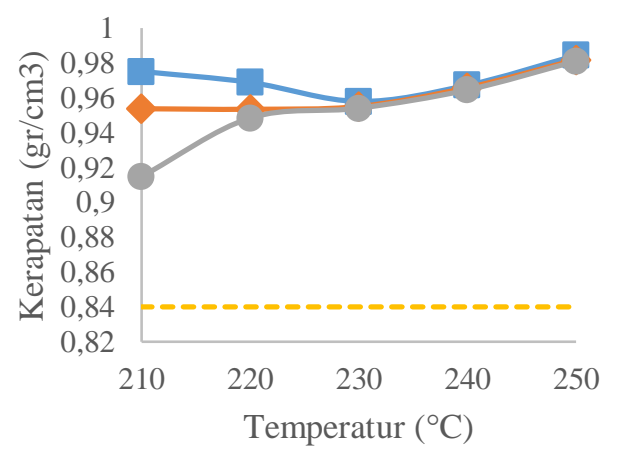

Gambar 3.1. Grafik Pengaruh Temperatur dan Kecepatan Putaran Screw terhadap Uji Kerapatan Papan Serat.

Pada Gambar 3.1, temperatur dan kecepatan putaran screw sangat berpengaruh terhadap nilai kerapatan, dimana semakin tinggi temperatur dan rendahnya kecepatan putaran screw maka campuran TKKS dan perekat plastik HDPE terhomogenasi dengan baik di dalam barrel dan dapat mengisi ruang cetakan yang sekaligus mampu memadatkan campuran TKKS dan HDPE dalam cetakan. Hal ini tentunya mampu menghindari terjadinya rongga-rongga pada papan serat dikarenakan telah terpadatkan 
oleh perekat HDPE. Namun apabila temperatur yang rendah dan kecepatan putaran screw yang tinggi, hal ini akan mengakibatkan sulitnya proses mixing dikarenakan perekat masih memiliki viskositas yang tinggi yang dapat menyulitkan proses homogenisasi, dengan tingginya kecapatan putaran screw mengakibatkan waktu tinggal selama proses mixing.

Kerapatan memiliki pengaruh terhadap sifat fisis lainnya, Menurut (Anton, 2012) menyatakan bahwa kerapatan papan serat memiliki pengaruh besar terhadap pengembangan tebal dan daya serap air pada papan serat. Rendahnya nilai kerapatan menyebabkan tingginya nilai pengembangan tebal dan daya serap air papan. Menurut (Mikael dkk., 2014) semakin tinggi kerapatan papan partikel dari suatu bahan baku tertentu maka semakin tinggi kekuatannya, tetapi kestabilan dimensinya menurun oleh naiknya kerapatan.

\section{Pengaruh Temperatur dan Kecepatan Screw Terhadap Uji Kadar Air Papan Serat}

Analisis kadar air bertujuan untuk mengetahui seberapa banyak kandungan air yang berada didalam papan serat. Kadar air papan serat merupakan jumlah air yang tertinggal di dalam rongga sel, dan rongga antar serat dan perekat selama proses ektrusi. Hal ini dapat menunjukan bahwa pembuatan papan serat dengan menggunakan screw extruder baik atau tidak. Batas kadar air papan serat yang baik berdasarakan Standar Nasional Indonesia No. 01-4449-2006 sebesar 13\%.

Hasil penelitian didapat papan serat dengan kadar air terendah yaitu pada temperatur $210^{\circ} \mathrm{C}$ dengan kecepatan putaran $20 \mathrm{rpm}$ sebesar $1,57 \%$, sedangkan kadar air yang tertinggi terdapat pada temperature $250^{\circ} \mathrm{C}$ dengan kecepatan putaran $60 \mathrm{rpm}$ sebesar 2,43 \%. Pada Gambar 3.4, dapat dilihat bahwa temperatur tidak begitu berpengaruh terhadap kadar air, tetapi temperatur juga perlu diperhatikan apabila temperatur operasi terlalu tinggi akan mengakibatkan munculnya uap air didalam barrel yang ikut terserap ke dalam campuran TKKS dan HDPE.

Kecepatan putaran screw sangat berpengaruh terhadap jumlah kadar air di dalam papan serat. Hal ini disebabkan karena laju aliran yang begitu cepat mengakibatkan campuran tidak merata sehingga masih terdapat rongga-rongga kosong yang nantinya akan terisi oleh uap air akibat dari proses ektrusi. Tingginya pressure flow pada ujung barrel akibat dari kecepatan putaran yang cepat juga dapat mengakibatkan meningkatnya tekanan aliran menuju die begitu besar, yang mengakibatkan tidak meratanya penyebaran TKKS dan HDPE dalam cetakan. 
Rancang Bangun Alat Screw Extruder Pembuatan Medium Density Fiberboard Berbasis Serat Tandan Kosong Kelapa Sawit dan Perekat High Density Polyethylene (Hdpe) (Uji Kinerja Alat Ditinjau dari Efisiensi Screw Extruder)

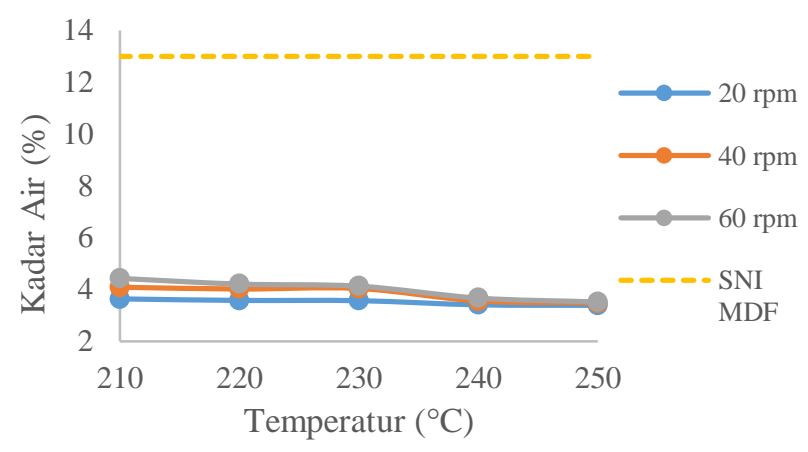

Gambar 3.2. Grafik Pengaruh Temperatur dan Kecepatan Putaran Screw terhadap Uji Kadar Air Papan Serat.

Kadar air yang tinggi pada papan serat dapat mengakibatkan ikatan rekat menjadi lemah. Menurut (Mikael dkk., 2014) menyatakan bahwa kadar air pada papan serat dipengaruhi oleh nilai kerapatannya, papan serat yang memiliki nilai kerapatan yang lebih tinggi mempunyai ikatan antar molekul serat dengan molekul perekat yang sangat kuat sehingga molekul air sulit untuk mengisi rongga yang terdapat dalam pembuatan papan partikel karena rongga tersebut terisi dengan molekul perekat.

\section{Pengaruh Temperatur dan Kecepatan Screw Terhadap Uji Daya Serap Air Papan Serat}

Analisis daya serap air bertujuan untuk mengukur kemampuan papan serat dalam menyerap air. Pada SNI No. 01-4449-2006, daya serap air untuk papan serat berkerapatan sedang tidak memiliki syarat tertentu, sedangkan untuk papan serat berkerapatan tinggi sebesar 20\%. Berdasarkan Gambar 3.3, terlihat bahwa papan serat yang memiliki daya serap air tertinggi yaitu pada temperatur operasi $210^{\circ} \mathrm{C}$ dan kecepatan putaran screw $60 \mathrm{rpm}$. Sedangkan daya serap air terendah berada pada temperatur operasi $250^{\circ} \mathrm{C}$ dengan kecepatan putaran screw $20 \mathrm{rpm}$. Hal ini menunjukan semakin tingginya kecepatan putaran screw maka semakin tinggi juga daya serap air terhadap papan serat. Hal tersebut disebabkan karena pada saat proses perendaman, air akan mengisi rongga-rongga kosong pada papan serat sehingga mengakibatkan air akan mudah masuk ke dalam papan serat.

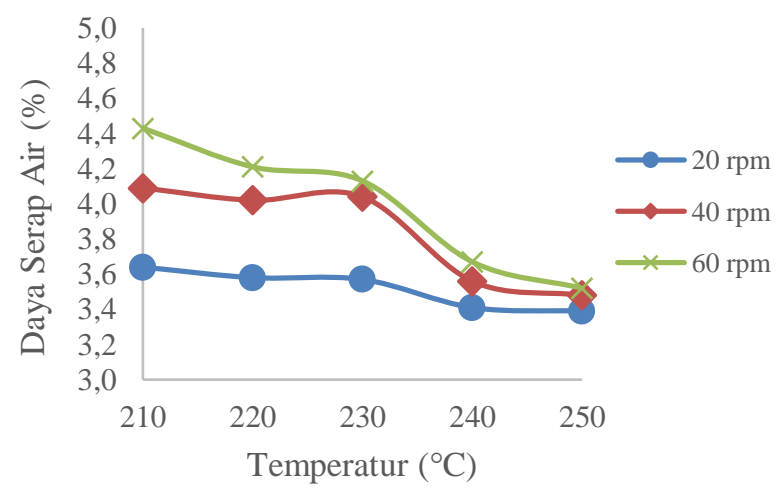


Muhamad Arif Rachman, Anerasari Meidinariasty, Selastia Yuliati.

Gambar 3.3. Grafik Pengaruh Temperatur dan Kecepatan Putaran Screw terhadap Uji Daya Serap Air Papan Serat.

Menurut (Septiari dan Kartowasono, 2017), selulosa yang terkandung dalam papan partikel mampu menyerap air pada saat proses perendaman papan serat dalam air dikarenakan adanya gaya absorbsi yang merupakan gaya tarik molekul air pada ikatan hidrogen yang terdapat dalam selulosa tersebut. Tentunya hal ini juga berpengaruh terhadap kerapatan papan dimana ikatan antar partikel akan semakin kompak dan menyebabkan rongga udara dalam lembaran papan akan semakin kecil. Keadaan tersebut akan menyebabkan air menjadi sulit untuk mengisi rongga papan partikel tersebut semakin kecil daya serap air papan partikel, maka stabilitas papan tersebut semakin baik, demikian pula sebaliknya.

\section{Pengaruh Temperatur dan Kecepatan Screw Terhadap Uji Pengembangan Tebal Papan Serat}

Analisis pengembangan tebal bertujuan untuk mengetahui perubahan dimensi serat akibat pengembangan dinding sel serat atau perbuhan ukuran rongga serat akibat menyerap air (Purnamasari, 2020). Berdasarkan analisis yang telah lakukan, diperoleh grafik pengaruh temperatur dan kecepatan putaran terhadap pengembangan tebal papan serat. Pada penelitian ini didapat nilai pengembangan tebal terendah terjadi pada kondisi operasi $250^{\circ} \mathrm{C}$ dan kecepatan putaran screw $20 \mathrm{rpm}$ sebesar 3,39\%. Sedangkan pengembangan tebal tertinggi berada pada kondisi operasi $210^{\circ} \mathrm{C}$ dan kecapatan putaran screw $60 \mathrm{rpm}$ sebesar $4,43 \%$.

(Anton, 2012) menjelaskan bahwa pertambahan pengembangan tebal seiring dengan pertambahan daya serap air papan serat. Serat semakin terlapisi dengan baik oleh perekat sehingga kontak antara serat dan air menjadi lebih kecil. Perekat yang memasuki dinding serat dan kemudian mengeras dapat menciptakan hambatan fisik (physical barrier) sehingga menyebabkan penurunan penyerapan air yang menyebabkan pengembangan tebal. Menurut (Purnamasari, 2020), sifat pengembangan tebal papan serat sejalan dengan sifat daya serap air, yaitu semakin banyak air yang diserap makin besar pengembangan tebalnya. Pengembangan tebal juga sejalan dengan tingkat kerapatan dimana nilai dengan kerapatan yang rendah tentunya membuat serat TKKS akan menarik air kembali sehingga serat-serat pada papan serat akan kembali menjadi bentuk semula akibat hilangnya tekanan setelah perendaman. 
Rancang Bangun Alat Screw Extruder Pembuatan Medium Density Fiberboard Berbasis Serat Tandan Kosong Kelapa Sawit dan Perekat High Density Polyethylene (Hdpe) (Uji

Kinerja Alat Ditinjau dari Efisiensi Screw Extruder)

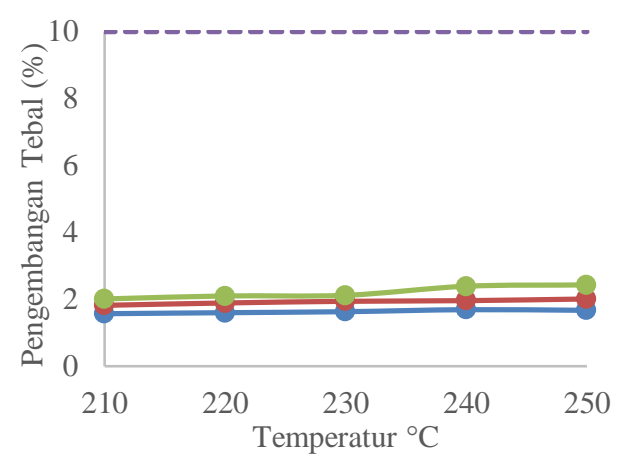

Gambar 3.4. Grafik Pengaruh Temperatur dan Kecepatan Putaran Screw terhadap Uji Pengembangan Tebal Papan Serat.

Pada Gambar 3.4., dapat dilihat bahwa temperatur dan kecepatan putaran berpengaruh terhadap nilai pengembangan tebal pada papan serat, dimana semakin cepat kecepatan putaran screw dan rendahnya temperatur, maka akan membuat campuran TKKS dan HDPE tidak terhomogenasi dengan baik sehingga masih terdapat serat serat yang tidak terlapisi oleh perekat dan juga akan sulit untuk mengisi ruang di dalam cetakan. Penggunaan perekat dalam pembuatan papan serat selain sebagai perekat juga berfungsi untuk mencegah air masuk kedalam papan.

\section{Kesimpulan}

Berdasarkan hasil penelitian yang telah dilakukan terkait perancangan alat Screw Extruder pada pembuatan papan serat dengan perbandingan komposisi bahan dan variasi kecepatan putaran screw dapat disimpulkan bahwa : 1. Telah dihasilkan sebuah protipe alat Screw Extruder untuk pembuatan Medium Density Fiberboard (MDF) atau Papan Serat Berkerapatan Sedang berbasis serat Tandan Kosong Kelapa Sawit (TKKS) sebagai bahan pengisi dan plastik High Density Polyethylene (HDPE) sebagai bahan perekat. 2. Dari variasi temperatur dan kecepatan putaran screw yang telah diujicobakan pada pembuatan papan serat, didapatkan kondisi optimum dengan temperatur operasi sebesar $210^{\circ} \mathrm{C}$ dan kecepatan putaran screw $20 \mathrm{rpm}$, dimana pada kondisi tersebut, nilai penyusutan (shrinkage) pada papan serat sangat kecil, dengan nilai kerapatan yang tinggi dan kadar air yang rendah. 3. Nilai efisiensi tertinggi berdasarkan shrinkage alat screw extruder yaitu pada temperatur $210^{\circ} \mathrm{C}$ dan kecepatan putaran screw $20 \mathrm{rpm}$ sebesar 97,17\%.. 4. Pada pembuatan papan partikel dengan menggunakan alat Screw Extruder menghasilkan papan sesuai standart Standar Nasional Indonesia No. 01-44492006, dimana untuk nilai kerapatan tertinggi yaitu pada temperatur $250^{\circ} \mathrm{C}$ kecepatan putaran screw $20 \mathrm{rpm}$, untuk nilai kadar air berada pada temperatur $210^{\circ} \mathrm{C}$ dan kecepatan putaran screw $20 \mathrm{rpm}$, Sedangkan daya serap, dan pengembangan tebal yaitu pada temperatur $250^{\circ} \mathrm{C}$ dengan kecepatan putaran $20 \mathrm{rpm}$ 
Muhamad Arif Rachman, Anerasari Meidinariasty, Selastia Yuliati.

\section{Bibliografi}

Anton, S. (2012). Pembuatan dan Uji Karakteristik Papan Partikel dari Serat Buah Bintaro (Cerbera Manghas).

Apriani, Enda. (2017). Analisa Pengaruh Variasi Komposisi Bahan Limbah Dari Serat Kelapa Muda, Batang Pisang Dan Kertas Bekas Terhadap Kekuatan Bending Sebagai Papan Komposit. Jurnal ENGINE, 1(2), 3846.http://dx.doi.org/10.30588/jeemm.v1i2.259

Aryo Satito. (2016). Rancang Bangun Mesin Wood Plastic Composite Screw Extrussion Molding. 01(June), 15-16.

Atmam, Tanjung, A., \& Zulfahri. (2018). Analisis Penggunaan Energi Listrik Motor Induksi Tiga Phasa Menggunakan Variable Speed Drive (VSD). SainETIn, 2(2), $52-59$. https://doi.org/10.31849/sainetin.v2i2.1218 https://doi.org/10.31849/sainetin.v2i2.1218

Badan Standardisasi Nasional. 2006. Mutu Papan Serat SNI 01-4449-2006. Bogor: Badan Standardisasi Nasional.https://doi.org/10.21009/jmenara.v7i2.7952

Kelly, A. L., Sorroche, J. V., Brown, E. C., \& Coates, P. D. (2014). IMPROVING THERMAL EFFICIENCY OF SINGLE SCREW EXTRUSION. Journal of Engineering, 1(April), 1-7.

Maradu, Sibrani. Muhammad Piky Allan. Putu M. San. (2018). Perancangan unit Extruder Pada Mesin Extrusion Laminasi Fleksible Packaging. Jurnal Teknik Mesin ITI, 2(2), 42-45. https://doi.org/10.31543/jtm.v2i2.155

Mawardi, Sumardi Indra. (2009). Perancangan dan fabrikasi mesin extrusi single screw. Jurnal POLIMESIN, 7(1), 602. https://doi.org/10.30811/jp.v7i1.1348

Mikael, I., Hartono, R., \& Sucipto, T. (2014). KUALITAS PAPAN PARTIKEL DARI CAMPURAN AMPAS TEBU DAN PARTIKEL MAHONI DENGAN BERBAGAI VARIASI KADAR PEREKAT PHENOL FORMALDEHIDA. Universitas Sumatera Utara.

Mikell, \& Groover. (2013). Fundamentals Of Modern Manufacturing. $5^{\text {th }}$ Edition

Purnamasari, Meri. (2020). Pembuatan Dan Karakterisasi Papan Seratdengan Variasi Tipe Serat Sabut Kelapa (Cocos nucifera) dan perekat plastik high density polyethylene dan low density polyethylene. Politeknik negeri sriwijaya.

Septiari, Ida Ayu Putu Wida, \& Kartowasono, Ngadiran. (2017). Pembuatan Papan Partikel dari Limbah Plastik Polyprophylene (PP) dan Tangkai Bambu. Jurnal Pendidikan Kimia Undiksha, 1(1).http://dx.doi.org/10.23887/jjpk.v1i1.4027 
Rancang Bangun Alat Screw Extruder Pembuatan Medium Density Fiberboard Berbasis Serat Tandan Kosong Kelapa Sawit dan Perekat High Density Polyethylene (Hdpe) (Uji Kinerja Alat Ditinjau dari Efisiensi Screw Extruder)

Silviyati, Idha, Supriaptiah, Endang, Ramadhan, Iqbal, \& Wulandari, Meiditha. (2019).

Pengaruh Penambahan High Density Poly Ethylene (Hdpe) Dan Oli Bekas Sebagai Binder Pada Bata Ringan Dengan Variasi Filler. Kinetika, Politeknik Negeri Sriwijaya, 10(03), 14-18.

Safrijal, Ali, S., \& Susanto, H. (2017). Pengujian Papan Komposit Diperkuat Serat Tandan Kosong Kelapa Sawit ( TKKS ) Dengan Menggunakan Alat Uji Impact Charpy. Jurnal Mekanova, 3(5), 158-167.https://doi.org/10.35308/jmkn.v3i1.864

Zulnazri, Suryati, \& Nasrun. (2014). Fabrikasi Material Komposit Plastik PP dan HDPE dengan Penguat Mikro Filler Tandan Kosong Kelapa Sawit dengan Proses Screw Extruder. Universitas Malikussaleh. 